\title{
Burden and correlates of cognitive impairment among hypertensive patients in Tanzania: a cross-sectional study
}

Pedro Pallangyo ${ }^{1,2^{*}}$, Zabella S. Mkojera ${ }^{1}$, Makrina Komba ${ }^{1}$, Lucy R. Mgopa ${ }^{1,3}$, Smita Bhalia ${ }^{2}$, Henry Mayala ${ }^{4}$, Salma Wibonela ${ }^{5}$, Nsajigwa Misidai ${ }^{1}$, Happiness J. Swai ${ }^{1}$, Jalack Millinga ${ }^{1,5}$, Ester Chavala ${ }^{1,5}$,

Peter R. Kisenge ${ }^{2}$ and Mohamed Janabi

\begin{abstract}
Background: The evolution of cognitive impairment of vascular origin is increasingly becoming a prominent health threat particularly in this era where hypertension is the leading contributor of global disease burden and overall health loss. Hypertension is associated with the alteration of the cerebral microcirculation coupled by unfavorable vascular remodeling with consequential slowing of mental processing speed, reduced abstract reasoning, loss of linguistic abilities, and attention and memory deficits. Owing to the rapidly rising burden of hypertension in Tanzania, we sought to assess the prevalence and correlates of cognitive impairment among hypertensive patients attending a tertiary cardiovascular hospital in Tanzania.
\end{abstract}

Methodology: A hospital-based cross-sectional study was conducted at Jakaya Kikwete Cardiac Institute, a tertiary care public teaching hospital in Dar es Salaam, Tanzania between March 2020 and February 2021. A consecutive sampling method was utilized to recruit consented hypertensive outpatients during their scheduled clinic visit. General Practitioner Assessment of Cognition (GPCOG) Score was utilized in the assessment of cognitive functions. All statistical analyses utilized STATA v11.0 software. Pearson Chi square and Student's T-test were used to compare categorical and continuous variables respectively. Logistic regression analyses were used to assess for factors associated with cognitive impairment. Odd ratios with 95\% confidence intervals and $p$-values are reported. All tests were 2 -sided and $p<0.05$ was used to denote a statistical significance.

Results: A total of 1201 hypertensive patients were enrolled in this study. The mean age was 58.1 years and females constituted nearly two-thirds of the study population. About three quarters had excess body weight, $16.6 \%$ had diabetes, $7.7 \%$ had history of stroke, 5.7\% had heart failure, 16.7\% had renal dysfunction, $53.7 \%$ had anemia, $27.7 \%$ had hypertriglyceridemia, $38.5 \%$ had elevated LDL, and $2.4 \%$ were HIV-infected. Nearly two-thirds of participants had uncontrolled blood pressure and 8.7\% had orthostatic hypotension. Overall, 524 (43.6\%) of participants had cognitive impairment. During bivariate analysis in a logistic regression model of 16 characteristics, 14 parameters showed association with cognitive functions. However, after controlling for confounders, multivariate analysis revealed $\leq$ primary education (OR 3.5, 95\% Cl 2.4-5.2, $p<0.001)$, unemployed state (OR 1.7, 95\%Cl 1.2-2.6, $p<0.01)$, rural habitation (OR

\footnotetext{
*Correspondence: pedro.pallangyo@gmail.com

2 Directorate of Cardiology, Jakaya Kikwete Cardiac Institute, P.O

Box 65141, Dar es Salaam, Tanzania

Full list of author information is available at the end of the article
} original author(s) and the source, provide a link to the Creative Commons licence, and indicate if changes were made. The images or other third party material in this article are included in the article's Creative Commons licence, unless indicated otherwise in a credit line to the material. If material is not included in the article's Creative Commons licence and your intended use is not permitted by statutory regulation or exceeds the permitted use, you will need to obtain permission directly from the copyright holder. To view a copy of this licence, visit http://creativecommons.org/licenses/by/4.0/. The Creative Commons Public Domain Dedication waiver (http://creativeco mmons.org/publicdomain/zero/1.0/) applies to the data made available in this article, unless otherwise stated in a credit line to the data. 
$1.8,95 \% \mathrm{Cl} 1.1-2.9, p=0.01)$ and renal dysfunction (OR $1.7,95 \% \mathrm{Cl} 1.0-2.7, p=0.04)$ to have independent association with cognitive impairment.

Conclusion: This present study underscore that cognitive decline is considerably prevalent among individuals with systemic hypertension. In view of this, it is pivotal to incorporate cognitive assessment in routine evaluation of hypertensive patients.

Keywords: Cognitive dysfunction, Cognitive impairment, Cognitive decline, Cognitive deficits, Arterial hypertension, Systemic hypertension, Hypertension, Elevated blood pressure, High blood pressure, Sub Saharan Africa, Jakaya Kikwete cardiac institute, Tanzania

\section{Background}

Systemic arterial hypertension, the leading cause of global disease burden and overall health loss, affects over two-fifths of the adult population worldwide[1-4]. Given the progressive ageing of the world population and considering the rapidly growing prevalence of uncontrolled hypertension, the evolution of cognitive impairment is increasingly becoming a prominent health threat. The World Health Organization (WHO) estimates that about two-thirds of the cerebrovascular disease is attributable to elevated blood pressure[5]. Furthermore, accruing epidemiological and mechanistic evidence suggests that hypertension is a risk factor for the onset and progression of cognitive impairment, vascular dementia and Alzheimer's disease[6-63]. In view of its pivotal role in cognitive impairment particularly of vascular origin, the WHO has set a global target to relatively reduce $25 \%$ of the hypertension burden by 2025 as a fundamental measure to reduce the risk of cognitive decline[64].

Although our current understanding predominantly emphasize on the well-established effect of high blood pressure in the development of stroke, the impact on cognitive consequences appears to be independent of stroke[38, 46]. The deleterious effects of hypertension on the brain targets the cerebral blood vessels with resultant structural and functional cerebrovascular alterations including white matter damage, frontal lobe dysfunction, small vessel disease, lacunar strokes, cerebral microhemorrhages, arteriosclerosis, silent brain infarcts, and brain atrophy[65-76]. As a consequence, hypertension is associated with reduced abstract reasoning (executive dysfunction), slowing of mental processing speed, loss of linguistic abilities, and attention and memory deficits[10, 77-80]. Owing to the paucity of data regarding the association between arterial hypertension and cognitive decline particularly in resource-limited settings, this present study aimed to explore the burden and correlates of cognitive impairment among hypertensive patients attending a tertiary cardiovascular hospital in Tanzania.

\section{Methods}

Study design, recruitment process, and definition of terms This hospital-based cross-sectional study was conducted at Jakaya Kikwete Cardiac Institute (JKCI), a tertiary care public teaching hospital in Dar es Salaam, Tanzania between March 2020 and February 2021. A consecutive sampling method was utilized to recruit consented hypertensive outpatients during their scheduled clinic visit. A structured questionnaire bearing questions pertaining to sociodemographic and clinical characteristics, measurement of key vitals (blood pressure [BP], blood sugar, height, and weight) was used during participants' interviews. Social activity, sleeping habits, vision/hearing status, mental health history, seizure disorders, dietary intake and history of stroke were self-reported.

The General Practitioner Assessment of Cognition (GPCOG), a cognitive impairment screening tool copyrighted by the University of New South Wales was utilized in the assessment of cognitive impairment. The GPCOG has been validated for use in a wide variety of populations including hypertension and resistant hypertension subpopulations. With a sensitivity and specificity for the English GPCOG ranging from 0.81 to 0.98 and 0.72 to 0.95 , respectively; the GPCOG performed at least as well as, if not better, than the widely-used cognitive screens such as the Mini-Mental State Examination (MMSE) or the Abbreviated Mental Test (AMT) [81]. The GPCOG consists of two parts: (i) a 9-items cognitive assessment (i.e. time orientation, visuospatial functioning, information and recall) conducted with the patient whereby a score of $0-4$ indicates cognitive impairment, a score of 5-8 signify inconclusive results and a score of 9 implies no significant cognitive impairment and warrants no further testing and (ii) a 6-questions informant questionnaire, which is only performed if the results of the cognitive assessment are inconclusive. If the patient scores $0-3$ out of 6 , cognitive impairment is indicated[81].

Physical activity was assessed using the Physical Activity Vital Sign (PAVS)[82] questionnaire whereby reported moderate-vigorous physical activity of $0 \mathrm{~min} /$ week, $<150 \mathrm{~min} /$ week, or $\geq 150 \mathrm{~min} /$ week was used to 
categorize participants as inactive, underactive or active respectively. We defined underweight as $\mathrm{BMI}<18.5 \mathrm{~kg} /$ $\mathrm{m}^{2}$, normal: BMI $18.5-24.9 \mathrm{~kg} / \mathrm{m}^{2}$, overweight: BMI $25.0-$ $29.9 \mathrm{~kg} / \mathrm{m}^{2}$ and obese: $\mathrm{BMI} \geq 30.0 \mathrm{~kg} / \mathrm{m}^{2}$ [83]. Individuals who smoked at least 1 cigarette in the past 6 months were regarded as current smokers, those who last smoked over 6 months or self-reported quitting smoking were considered ex-smokers and those who never smoked were regarded as never-smokers. Alcohol drinking was defined as at least a once consumption every week. Social activeness was assessed through participants' self-assessment (i.e. active vs inactive) regarding their participation in important social activities (i.e. weddings, burial ceremonies, and traditional festivals).

Hypertension was defined as SBP $\geq 140 \mathrm{mmHg}$ or DBP $\geq 90 \mathrm{mmHg}$, and/or use of BP lowering agents[84]. Moreover, SBP $\geq 140 \mathrm{mmHg}$ or DBP $\geq 90 \mathrm{mmHg}$ was used to define uncontrolled BP. Orthostatic hypotension was defined by a decrease in SBP $\geq 20 \mathrm{mmHg}$ or DBP $\geq 10 \mathrm{mmHg}$ within $3 \mathrm{~min}$ of standing when compared to the sitting measurements. Diabetes was diagnosed using a glycated hemoglobin (HbA1c) of $\geq 6.5 \%$ and/or fasting blood glucose (FBG) $\geq 7 \mathrm{mmol} / \mathrm{L}$ or use of glucose-lowering agents[85]. A 2-dimensional echocardiography was utilized for the diagnosis heart failure. Renal functions were estimated using the Modification of Diet in Renal Disease (MDRD) equation and renal dysfunction was defined by an estimated glomerular filtration rate (eGFR) value of $<60 \mathrm{~mL} / \mathrm{min} / 1.73 \mathrm{~m}^{2}[86]$.WHO criteria for anemia i.e. hemoglobin $(\mathrm{Hb})$ concentration of $<13.0 \mathrm{~g} / \mathrm{dL}$ for males and $<12.0 \mathrm{~g} / \mathrm{dL}$ for females was used to diagnose anemia[87]. Triglycerides and low-density lipoprotein (LDL) cut-off levels of $1.7 \mathrm{mmol} / \mathrm{L}$ [88] and $3.5 \mathrm{mmol} / \mathrm{L}[89]$ respectively were used to categorize hypertriglyceridemia and elevated LDL respectively. Uric acid levels of $480 \mu \mathrm{mol} / \mathrm{L}$ and $360 \mu \mathrm{mol} / \mathrm{L}$ were used to denote hyperuricemia among males and females respectively[90].

\section{Statistical analysis}

All statistical analyses utilized STATA v11.0 software. Summaries of continuous variables and categorical variables are presented as are presented as means $( \pm \mathrm{SD})$ and frequencies (percentages) respectively. Pearson Chi square and Student's T-test were used in comparison of categorical and continuous variables respectively. Logistic regression analyses were used to assess for factors associated with cognitive impairment. Stepwise and forward selection procedure was used to add and assess the statistically significant variables in the multivariate regression model. The multivariate model was fitted with baseline covariates associated with cognitive impairment by bivariate analysis at the $<0.05$ significance level. Odd ratios (OR) with $95 \%$ confidence intervals and $p$-values are reported. All tests were 2 -sided and $p<0.05$ was used to denote a statistical significance.

\section{Results \\ Study population characteristics}

A total of 1201 hypertensive patients were enrolled in this study. Table 1, displays sociodemographic and clinical characteristics of study participants. The mean age was 58.1 years and just over a half of all participants were aged 60 years or more. Nearly two-thirds $(64.4 \%)$ of all participants were female, $71.2 \%$ were married, $66.3 \%$ had a regular income generating activity, and $65.0 \%$ had attained at most primary education. Large majority $(83.1 \%)$ resided in urban areas and $92.0 \%$ lived with their families. About $1 \%$ were current smokers, $6.6 \%$ consumed alcohol, and $86.3 \%$ were socially active. Over a quarter $(27.3 \%)$ of all participants were physically active and about three quarters $(75.7 \%)$ were overweight or obese. Over one-third had insomnia (36.3\%), 16.6\% had diabetes, $7.7 \%$ had history of stroke, $5.7 \%$ had heart failure, $16.7 \%$ had renal dysfunction, $53.7 \%$ had anemia, $32.4 \%$ had hyperuricemia, $27.7 \%$ had hypertriglyceridemia, $38.5 \%$ had elevated LDL, and $2.4 \%$ were HIV-infected. Nearly two-thirds (65.4\%) of participants had uncontrolled BP and $8.7 \%$ had orthostatic hypotension.

\section{Prevalence of cognitive impairment}

Overall, 524 (43.6\%) of participants had cognitive impairment. Compared to participants with preserved cognition, individuals with cognitive impairment were older (i.e. mean age 61.1 vs 55.7 years, $p<0.001$ ) and had a higher proportion of those aged $\geq 60$ years (i.e. $60.9 \%$ vs $42.1 \%, p<0.001)$. Females comprised a higher proportion of the cognitive impairment group, $69.9 \%$ vs $60.3 \%, p<0.001$. There was a higher proportion of participants with $\leq$ primary education level $(80.0 \%$ vs $53.3 \%$, $\mathrm{p}<0.001)$, unmarried status $(35.5 \%$ vs $23.6 \%, \mathrm{p}<0.001)$, no regular income generating activity $(53.4 \%$ vs $32.9 \%$, $\mathrm{p}<0.001)$ and rural residents $(22.7 \%$ vs $12.4 \%, \mathrm{p}<0.001)$ in the group with impaired cognitive functions. Moreover, physically and socially inactive participants were significantly higher in the group with cognitive impairment, i.e. $23.9 \%$ vs $17.0 \%, p<0.01$ and $18.9 \%$ vs $9.6 \%, \mathrm{p}<0.001$ respectively. Furthermore, participants with cognitive impairment displayed a higher proportion of insomnia $(42.4 \%$ vs $31.6 \%, p<0.001)$, orthostatic hypotension $(10.9 \%$ vs $6.9 \%, \mathrm{p}<0.001)$ and renal dysfunction $(20.6 \%$ vs $13.5 \%, p<0.01)$.

\section{Correlates of cognitive impairment}

Table 2 displays the results of logistic regression analyses for factors associated with cognitive impairment. 
Table 1 Sociodemographic and clinical characteristics of study participants by cognitive status

\begin{tabular}{|c|c|c|c|c|}
\hline Characteristic & $\begin{array}{l}\text { All } \\
N=1201\end{array}$ & $\begin{array}{l}\text { Preserved Cognition } \\
n=677\end{array}$ & $\begin{array}{l}\text { Cognitive Dysfunction } \\
n=524\end{array}$ & $p$-value \\
\hline \multicolumn{5}{|l|}{ Age } \\
\hline Mean (SD) & $58.1(11.3)$ & $55.7(10.9)$ & $61.1(11.1)$ & $<0.001$ \\
\hline$<60$ years & $597(49.7 \%)$ & $392(57.9 \%)$ & 205 (39.1\%) & \\
\hline$\geq 60$ years & $604(50.3 \%)$ & $285(42.1 \%)$ & 319 (60.9\%) & $<0.001$ \\
\hline \multicolumn{5}{|l|}{ Sex } \\
\hline Male & $427(35.6 \%)$ & $269(39.7 \%)$ & $158(30.1 \%)$ & \\
\hline Female & 774 (64.4\%) & $408(60.3 \%)$ & 366 (69.9\%) & $<0.001$ \\
\hline \multicolumn{5}{|l|}{ Education level } \\
\hline No formal & $74(06.2 \%)$ & $16(02.3 \%)$ & $58(11.1 \%)$ & $<0.001$ \\
\hline Primary & $706(58.8 \%)$ & $345(51.0 \%)$ & $361(68.9 \%)$ & $<0.001$ \\
\hline Secondary & $279(23.2 \%)$ & $203(30.0 \%)$ & $76(14.5 \%)$ & $<0.001$ \\
\hline University & $142(11.8 \%)$ & $113(16.7 \%)$ & 29 (05.5\%) & $<0.001$ \\
\hline \multicolumn{5}{|l|}{ Marital status } \\
\hline Single & 40 (03.3\%) & $23(03.4 \%)$ & $17(03.2 \%)$ & 0.85 \\
\hline Married & $855(71.2 \%)$ & $517(76.4 \%)$ & $338(64.5 \%)$ & $<0.001$ \\
\hline Divorced & $68(05.7 \%)$ & $36(05.3 \%)$ & $32(06.1 \%)$ & 0.55 \\
\hline Widowed & $238(19.8 \%)$ & $101(14.9 \%)$ & $137(26.2 \%)$ & $<0.001$ \\
\hline \multicolumn{5}{|l|}{ Occupation } \\
\hline Student & $3(0.3 \%)$ & $2(0.3 \%)$ & $1(0.2 \%)$ & 0.91 \\
\hline Unemployed & $292(24.3 \%)$ & 97 (14.3\%) & $195(37.2 \%)$ & $<0.001$ \\
\hline Self employed & $504(42.0 \%)$ & $313(46.2 \%)$ & $191(36.5 \%)$ & $<0.001$ \\
\hline Employed & $194(16.1 \%)$ & $141(20.9 \%)$ & $53(10.1 \%)$ & $<0.001$ \\
\hline Retired & $208(17.3 \%)$ & $124(18.3 \%)$ & $84(16.0 \%)$ & 0.30 \\
\hline \multicolumn{5}{|l|}{ Residence } \\
\hline Urban & 998 (83.1\%) & $593(87.6 \%)$ & 405 (77.3\%) & \\
\hline Rural & $203(16.9 \%)$ & $84(12.4 \%)$ & $119(22.7 \%)$ & $<0.001$ \\
\hline \multicolumn{5}{|l|}{ Cigarette smoking } \\
\hline Never & 1042 & $593(87.6 \%)$ & $449(85.7 \%)$ & 0.34 \\
\hline Ex-smoker & $(86.8 \%)$ & 74 (10.9\%) & $72(13.7 \%)$ & 0.14 \\
\hline Current & $\begin{array}{l}146(12.2 \%) \\
13(01.0 \%)\end{array}$ & $10(01.5 \%)$ & $3(0.6 \%)$ & 0.14 \\
\hline \multicolumn{5}{|l|}{ Alcohol drinking } \\
\hline Never & $705(58.7 \%)$ & $374(55.2 \%)$ & $331(63.2 \%)$ & $<0.01$ \\
\hline Past & $417(34.7 \%)$ & $243(35.9 \%)$ & $174(33.2 \%)$ & 0.33 \\
\hline Current & $79(06.6 \%)$ & $60(08.9 \%)$ & $19(03.6 \%)$ & $<0.001$ \\
\hline \multicolumn{5}{|l|}{ Physical activity } \\
\hline Mean (min/week) & $97.5(102.5)$ & $104.2(104.8)$ & $88.7(98.9)$ & $<0.01$ \\
\hline Inactive & $240(20.0 \%)$ & $115(17.0 \%)$ & $125(23.9 \%)$ & $<0.01$ \\
\hline Underactive & $635(52.9 \%)$ & $366(54.0 \%)$ & $269(51.3 \%)$ & 0.35 \\
\hline Active & $326(27.1 \%)$ & $196(29.0 \%)$ & $130(24.8 \%)$ & 0.10 \\
\hline Socially active & $1037(86.3 \%)$ & $612(90.4 \%)$ & $425(81.1 \%)$ & $<0.001$ \\
\hline \multicolumn{5}{|l|}{ Comorbidities: } \\
\hline Stroke & $92(07.7 \%)$ & $43(06.4 \%)$ & 49 (09.4\%) & 0.05 \\
\hline Significant head injury & $60(05.0 \%)$ & $33(04.9 \%)$ & $27(05.2 \%)$ & 0.81 \\
\hline Seizure disorder & $3(0.3 \%)$ & $2(0.3 \%)$ & $1(0.2 \%)$ & 0.73 \\
\hline Psychiatric illness & $22(01.8 \%)$ & $14(02.1 \%)$ & $8(01.5 \%)$ & 0.44 \\
\hline Vision/Hearing impairment & $583(48.5 \%)$ & $312(46.1 \%)$ & $271(51.7 \%)$ & 0.05 \\
\hline Insomnia & $436(36.3 \%)$ & $214(31.6 \%)$ & $222(42.4 \%)$ & $<0.001$ \\
\hline Anemia $^{a}$ & $281(53.7 \%)$ & $145(50.7 \%)$ & $136(57.4 \%)$ & 0.13 \\
\hline
\end{tabular}


Table 1 (continued)

\begin{tabular}{|c|c|c|c|c|}
\hline Characteristic & $\begin{array}{l}\text { All } \\
N=1201\end{array}$ & $\begin{array}{l}\text { Preserved Cognition } \\
n=677\end{array}$ & $\begin{array}{l}\text { Cognitive Dysfunction } \\
n=524\end{array}$ & $p$-value \\
\hline Iron deficiency anemia ${ }^{a}$ & $76(14.5 \%)$ & $38(13.3 \%)$ & $38(16.0 \%)$ & 0.38 \\
\hline Anemia of chronic illness ${ }^{a}$ & $114(21.8 \%)$ & $61(21.3 \%)$ & $53(22.4 \%)$ & 0.76 \\
\hline \multicolumn{5}{|l|}{ Dyslipidemia } \\
\hline Elevated Triglycerides ${ }^{a}$ & $94(27.7 \%)$ & $48(24.7 \%)$ & $46(31.7 \%)$ & 0.16 \\
\hline Elevated $\mathrm{LDL}^{\mathrm{a}}$ & 139 (38.5\%) & $86(42.0 \%)$ & $53(34.0 \%)$ & 0.12 \\
\hline Low $\mathrm{HDL}^{\mathrm{a}}$ & $144(49.0 \%)$ & $72(44.2 \%)$ & $72(55.0 \%)$ & 0.07 \\
\hline Hyperuricemia $^{a}$ & $97(32.4 \%)$ & $56(32.9 \%)$ & $41(31.8 \%)$ & 0.83 \\
\hline Diabetes mellitus & 199 (16.6\%) & $105(15.5 \%)$ & $94(17.9 \%)$ & 0.26 \\
\hline HIV & $29(02.4 \%)$ & $14(02.1 \%)$ & $15(02.9 \%)$ & 0.38 \\
\hline Renal dysfunction ${ }^{a}$ & $103(16.7 \%)$ & $46(13.5 \%)$ & $57(20.6 \%)$ & $<0.01$ \\
\hline Heart Failure & $68(05.7 \%)$ & $36(05.3 \%)$ & $32(06.1 \%)$ & 0.56 \\
\hline \multicolumn{5}{|l|}{ Body Mass Index } \\
\hline Mean (SD) & $29.5(6.1)$ & $29.9(6.0)$ & $28.9(6.2 \%)$ & $<0.01$ \\
\hline Underweight & $15(01.3 \%)$ & $6(0.9 \%)$ & $9(1.7 \%)$ & 0.20 \\
\hline Normal & 277 (23.1\%) & $138(20.4 \%)$ & $139(26.5 \%)$ & 0.01 \\
\hline Overweight & $392(32.6 \%)$ & $222(32.8 \%)$ & $170(32.4 \%)$ & 0.88 \\
\hline Obese & $517(43.1 \%)$ & $311(45.9 \%)$ & $206(39.3 \%)$ & 0.02 \\
\hline \multicolumn{5}{|l|}{ Blood Pressure } \\
\hline Controlled BP & $416(34.6 \%)$ & $233(34.4 \%)$ & $183(34.9 \%)$ & 0.86 \\
\hline Postural hypotension & 104 (08.7\%) & $47(06.9 \%)$ & $57(10.9 \%)$ & $<0.001$ \\
\hline
\end{tabular}

${ }^{a}$ : represents a subset of participants with respective lab results

Table 2 Logistic regression analyses for factors associated with cognitive impairment

\begin{tabular}{|c|c|c|c|c|c|c|c|}
\hline Characteristic & Comparison & OR & $95 \% \mathrm{Cl}$ & $p$-value & Adj.OR & $95 \% \mathrm{Cl}$ & $p$-value \\
\hline Age $\geq 60$ years & $<60$ years & 2.1 & $1.7-2.7$ & $<0.001$ & 1.3 & $0.8-1.9$ & 0.26 \\
\hline Female & Male & 1.5 & $1.2-1.9$ & 0.001 & 1.2 & $0.8-1.8$ & 0.51 \\
\hline$\leq$ Primary Education & $\geq$ Secondary Education & 3.5 & $2.7-4.5$ & $<0.001$ & 3.5 & $2.4-5.2$ & $<0.001$ \\
\hline Single/Divorced/Widowed & Married & 1.8 & $1.4-2.3$ & $<0.001$ & 1.1 & $0.8-1.7$ & 0.50 \\
\hline Unemployed/Retired & Self-employed/Employed & 2.3 & $1.8-3.0$ & $<0.001$ & 1.7 & $1.2-2.6$ & $<0.01$ \\
\hline Rural & Urban & 2.1 & $1.5-2.8$ & $<0.001$ & 1.8 & $1.1-2.9$ & 0.01 \\
\hline Current alcohol drinker & Non drinker & 0.7 & $0.6-0.9$ & $<0.01$ & 0.8 & $0.5-1.1$ & 0.16 \\
\hline Inactive/underactive & Physically active & 1.2 & $1.0-1.6$ & 0.11 & - & - & - \\
\hline Socially inactive & Socially active & 2.2 & $1.6-3.1$ & $<0.001$ & 1.1 & $0.7-1.8$ & 0.72 \\
\hline Vision/hearing impairment & No impairment & 1.3 & $1.0-1.6$ & 0.05 & 1.3 & $0.9-1.8$ & 0.20 \\
\hline History of stroke & No stroke & 1.5 & $1.0-2.3$ & 0.05 & 1.2 & $0.6-2.2$ & 0.60 \\
\hline insomnia & Regular sleep & 1.6 & $1.3-2.0$ & $<0.001$ & 1.2 & $0.9-1.8$ & 0.25 \\
\hline Renal dysfunction & Normal renal functions & 1.7 & $1.1-2.5$ & 0.02 & 1.7 & $1.0-2.7$ & 0.04 \\
\hline Diabetes mellitus & Diabetes-free & 1.2 & $0.9-1.6$ & 0.29 & - & - & - \\
\hline $\mathrm{BMI} \geq 25$ & $\mathrm{BMl}<25$ & 0.7 & $0.5-0.9$ & $<0.01$ & 0.8 & $0.5-1.2$ & 0.76 \\
\hline Postural hypotension & No postural hypotension & 1.6 & $1.1-2.5$ & 0.02 & 1.0 & $0.5-1.9$ & 0.98 \\
\hline
\end{tabular}

During bivariate analysis in a logistic regression model of 16 characteristics, 14 characteristics i.e. age $\geq 60$ years, female sex, sprimary education, single/divorced/ widowed status, unemployed/retired state, rural residence, non-drinker, social inactivity, vision/hearing deficits, history of stroke, insomnia, renal dysfunction, excess body weight and postural hypotension showed association with cognitive functions. However, after controlling for confounders, a multivariate analysis revealed $\leq$ primary education (OR 3.5, 95\%CI 2.4-5.2, 
$\mathrm{p}<0.001$ ), unemployed/retired state (OR 1.7, 95\%CI 1.2-2.6, $\mathrm{p}<0.01$, rural residence (OR 1.8, 95\%CI 1.1-2.9, $p=0.01$ ) and renal dysfunction (OR 1.7, 95\%CI 1.0-2.7, $p=0.04)$ to have independent association with cognitive impairment.

\section{Discussion}

Owing to the aging global populations, cognitive impairment is increasingly becoming a pivotal societal challenge and a threat to sustainable development. Strong evidence supporting the cumulative deleterious effect of chronic arterial hypertension on cognitive function exists. Indeed, hypertension is the most important modifiable risk factor for cerebral white matter lesions, cognitive impairment, lacunar infarction, microbleeds, stroke, and vascular dementia[91, 92]. Pathophysiological mechanisms underpinning this complex yet intriguing association are not completely elucidated, however, summation of the cerebrovascular and degenerative lesions hypothesis is entertained[91, 92]. Nonetheless, with conflicting results between studies, the benefits of blood pressure control on cognitive functions among individuals with hypertension remains unclear[12, 43, 93-107]. Moreover, with the absence of effective disease-modifying treatments, hypertension being a modifiable risk factor represents a potentially vital mechanism for prevention or delay of cognitive impairment.

Over two-fifth of participants with hypertension in this present study had cognitive impairment. There is a wide variability in the prevalence of cognitive impairment (16.5-63.9\%)[108-112] among persons with hypertension in the literature, however, our rate falls in between. Such discrepancy in the prevalence could be a result of the differences in population characteristics and variability in tools utilized for assessment of cognitive functions among studies. Nevertheless, comparative studies have consistently demonstrated superior rates of cognitive impairment to normotensive subjects[21, 110-112]. For instance, in a study by Muela HC et al.,[112] hypertensive individuals demonstrated twice as much prevalence of cognitive impairment compared to their normotensive counterparts (i.e. $50 \%$ vs $25 \%, p<0.001$ ). Furthermore, Muela[112] and colleagues revealed that patients with hypertension had worse performance in language, processing speed, visuospatial abilities, and memory upon neuropsychological tests. Likewise, in a study by Heizhat $M$ et al.,[21] hypertensive individuals had significantly lower each item score and total score of the MMSE, compared to the normotensive controls.

A reciprocal interplay between education and cognitive functions has been observed across studies[113, 114]. Despite the lack of a formal consensus regarding the definition of low education, it is considered the most effective modifiable risk factor for cognitive impairment globally[115-117]. Recent analyses have noted that education does change the point at which accelerated declines due to cognitive impairment occur[118]. In this present study, participants with low education had over three-fold chance of having cognitive impairment and indeed it was the strongest predictor. These findings are consistent with a meta-analysis by Meng X and D'Arcy C which revealed a pooled OR of 2.61 for cognitive impairment among those with low education[119]. Educational attainment contributes to individual differences in cognitive skills hence people with higher education perform better across a broad range of cognitive tasks[120]. Moreover, current data shows that continuing education and cognitive leisure activities increase cognitive reserve thus improving cognitive functions and lower incidence of cognitive impairment[121].

The mechanism underlying the influence of ruralurban differences on cognitive functions is complex and poorly understood. Conversely, the impact of urbanization is profound and potentially mediated by several factors including education and occupation, living environments and pollution, access to public resources and healthcare, amongst others. Over the years and across all geographical boundaries, studies have demonstrated that individuals residing in rural areas have inferior cognitive functions compared to their age- and sex-matched urban counterparts[122-129]. In this study, persons who resided in rural areas had an $80 \%$ increased odds of having cognitive impairment compared to their urban counterparts. Such findings echo the one from a Taiwanese study by Liu CC et al. which revealed a $90 \%$ increased odds among rural dwellers.[130] Furthermore, studies by Chuang YF and Nakamura K revealed an odds of 2.3 and 4.0 respectively among rural residents[131, 132]. These regional differences in rates of cognitive impairment suggests the presence of modifiable factors with potential interventional implications, which ought to be elucidated in future studies.

A complex triad relationship between employment, cognition, and diseases exists. Through repetitive participation in demanding, complex tasks often requiring considerable focus and expertise, employment has the potential to augment cognitive reserve, facilitate brain health and optimize cognitive functioning as it entail learning of new skills, establishing a routine and social engagement[133-139]. The odds of cognitive impairment among unemployed/retired participants of this study was 1.7. In unison to our findings, a study by Leist AK et al.,[140] revealed an odds of 1.2 in unemployed individuals. Among unemployed/retired individuals, negative neuroplasticity with resultant compromise of cognitive functioning could ensue from the lack of cognitive 
stimulation provided from employment engagement. Moreover, owing to its potential in leading to effective cognitive interventions and in order to promote successful cognitive aging, it is imperative for clinicians to consider educating patients about the importance of staying cognitively active regardless of their employment status.

Epidemiologic data suggest that individuals at all stages of renal dysfunction have increased risk of developing cognitive disorders[141-153]. Consistent with previous research, this present study demonstrated a $70 \%$ increased likelihood of cognitive impairment among participants with renal dysfunction compared to their counterparts with preserved renal functions. Despite of its poorly understood pathophysiology, the relationship between cognitive impairment and renal dysfunction appears to be complex and bidirectional[154-156]. Nevertheless, direct neuronal injury from uremic toxins and the high prevalence of both subclinical and symptomatic ischemic cerebrovascular lesions are conceivable underlying mechanisms[157]. It is postulated that, for every decrease of $15 \mathrm{ml} / \mathrm{min} / 1.73 \mathrm{~m}^{2}$ in glomerular filtration rate, there is a decline in cognitive function similar to that of a 3-year aging[145]. Furthermore, cognitive impairment in individuals with renal dysfunction is associated with poor health-related quality of life, longer hospitalizations and higher mortality[158].

\section{Strengths and limitations}

Several strengths can be drawn from this study including; (i) an adequate sample to estimate the prevalence of cognitive impairment and conduct analyses stratified according to potential effect modifiers, (ii) the use of standardized tools for data collection and utilization of qualified and competent personnel in all measurements, (iii) enrolled patients were attended in a tertiary hospital with a national status receiving cases from the whole country and thus our findings are perhaps generalizable to Tanzania and similar resource limited settings. Nevertheless, this study is not short of limitations. As this was the first local study to assess cognitive impairment, there was no normative data for comparison thus our cognitive impairment estimates could be over- or under-estimated. Lack of a non-hypertensive group for comparison prevents conclusions about whether cognitive impairment is linked to hypertension itself. Moreover, participants attending this tertiary level hospital may be systematically different to those attending lower level healthcare centers and thus our findings may not be generalizable to all populations in Tanzania. Furthermore, owing to the cross-sectional design, this study cannot preclude bias (i.e. referral filter bias) and limits both causality exploration and generalizability of findings. To elucidate the true nature and magnitude of this intriguing association, prospective studies are required to explore the longitudinal association between hypertension and incidence of cognitive impairment.

\section{Conclusion}

In conclusion, this present study underscore that cognitive decline is highly prevalent among individuals with systemic hypertension. In view of this, it is pivotal to incorporate cognitive assessment in routine evaluation of hypertensive patients.

\section{Abbreviations \\ 95\% Cl: 95\% Confidence Interval; AMT: Abbreviated Mental Test; BMI: Body mass index; BP: Blood pressure; CKD: Chronic kidney disease; DBP: Diastolic blood pressure; eGFR: Estimated glomerular filtration rate; FBG: Fasting blood glucose; GPCOG: General Practitioner Assessment of Cognition Score; Hb: Hemoglobin; HIV: Human immunodeficiency virus; IQR: Interquartile range; JKCl: Jakaya Kikwete Cardiac Institute; JKCI-IRB: Jakaya Kikwete Cardiac Institute -Institutional Review Board; LDL: Low-density lipoprotein; MDRD: Modification of Diet in Renal Disease equation; MMSE: Mini-Mental State Examination; OR: Odd Ratio; PAVS: Physical Activity Vital Sign Questionnaire; RBG: Random blood glucose; SBP: Systolic blood pressure; SD: Standard deviation; WHO: World Health Organization.}

\section{Supplementary Information}

The online version contains supplementary material available at https://doi. org/10.1186/s12883-021-02467-3.

\section{Additional file 1.}

\section{Additional file 2.}

\section{Acknowledgements}

We extend our gratitude to all participants for their willingness, tolerance and cooperation offered during this study.

\section{Authors' contributions}

PP conceived the study. LRM, MK, JM, NM, and HJS conducted all the interviews, as well as anthropometric and blood pressure measurements. ZSM entered all the data. HM, EC, SB, SW, PRK and MJ participated in patient management. PP performed all the data cleaning and analysis. The corresponding author (PP) wrote the first draft of the manuscript, and other authors contributed to and approved it. All authors made the decision to submit the manuscript for publication. All authors undertake responsibility for the accuracy and integrity of the analysis.

\section{Funding}

This study was sponsored by the PédPäl Research Initiative.

\section{Availability of data and materials}

The datasets used and/or analyzed during the current study available from the corresponding author on reasonable request.

\section{Declarations}

Ethics approval and consent to participate

The study protocol was submitted to, and approved by the Jakaya Kikwete Cardiac Institute - Institutional Review Board (JKCl-IRB). Written informed consent was obtained from all study participants. This research was conducted in accordance with the Declaration of Helsinki.

Consent for publication

Not applicable. 


\section{Competing interests}

The authors have no conflict of interest to declare.

\section{Author details}

${ }^{1}$ PédPäl Research Initiative, P.O Box 65066, Dar es Salaam, Tanzania. ${ }^{2}$ Directorate of Cardiology, Jakaya Kikwete Cardiac Institute, P.O Box 65141, Dar es Salaam, Tanzania. ${ }^{3}$ Department of Psychiatry and Mental Health, Muhimbili University of Health and Allied Sciences, P.O Box 65001, Dar es Salaam, Tanzania. ${ }^{4}$ Directorate of Clinical Support Services, Jakaya Kikwete Cardiac Institute, P.O Box 65141, Dar es Salaam, Tanzania. ${ }^{5}$ Directorate of Nursing, Jakaya Kikwete Cardiac Institute, P.O Box 65141, Dar es Salaam, Tanzania.

Received: 22 June 2021 Accepted: 25 October 2021

Published online: 08 November 2021

\section{References}

1. Leung AA, Daskalopoulou SS, Dasgupta K, et al. Hypertension Canada's 2017 guidelines for diagnosis, risk assessment, prevention, and treatment of hypertension in adults. Can J Cardiol. 2017;33:557-76.

2. Forouzanfar MH, Liu P, Roth GA, et al. Global burden of hypertension and systolic blood pressure of at least 110 to 115 mm hg, 1990-2015. JAMA. 2017:317:165-82.

3. Mozaffarian D, Benjamin EJ, Go AS, et al. American Heart Association statistics committee and stroke statistics subcommittee. Heart disease and stroke statistics-2015 update: a report from the American Heart Association [published corrections appear in Circulation. 2015; $131: e 535$ and Circulation. 2016; 133:e417]. Circulation. 2015; 131:e29-e322.

4. Lim SS, Vos T, Flaxman AD, et al. A comparative risk assessment of burden of disease and injury attributable to 67 risk factors and risk factor clusters in 21 regions, 1990-2010: a systematic analysis for the global burden of disease study 2010 [published corrections appear in Lancet. 2013:381:628 and Lancet. 2013:381:1276]. Lancet. 2012: 380:2224-2260.

5. Whitworth JA. World Health Organization $(\mathrm{WHO}) /$ International Society of Hypertension (ISH) statement on management of hypertension. J Hypertens. 2003;21:1983-92

6. Hughes TM, Sink KM. Hypertension and its role in cognitive function: current evidence and challenges for the future. Am J Hypertens. 2016;29:149-57.

7. McDonald C, Pearce MS, Kerr SR, et al. Blood pressure variability and cognitive decline in older people: a 5-year longitudinal study. J Hypertens. 2017:35:140-7.

8. Kivipelto M, Helkala EL, Hanninen T, et al. Midlife vascular risk factors and late-life mild cognitive impairment. A population-based study. Neurology. 2001;56:1683-9.

9. Kuller $\mathrm{LH}$, Lopez $\mathrm{OL}$, Jagust WJ, et al. Determinants of vascular dementia in the cardiovascular health cognition study. Neurology. 2005;64:1548-52.

10. Gąsecki D, Kwarciany M, Nyka W, et al. Hypertension, brain damage, and cognitive decline. Curr Hypertens Rep. 2013;15:547-58.

11. Haring B, Wu C, Coker LH, et al. Hypertension, dietary sodium, and cognitive decline: results from the Women's health initiative memory study. Am J Hypertens. 2016;29:202-16.

12. In't Veld BA, Ruitenberg A, Hofman A, et al. Antihypertensive drugs and incidence of dementia: the Rotterdam study. Neurobiol Aging. 2001;22:407-12

13. Aronow WS. Hypertension and cognitive impairment. Ann Transl Med 2017;5(12):259.

14. Baranowski J, Klęczar K, Sołtysiak M, Widecka K. The association between cognitive decline and short-term blood pressure variability in middle-aged patients with primary hypertension - a pilot study. Arterial Hypertens. 2018;22(3):135-42.

15. Jung HW, Kim Kl. Blood pressure variability and cognitive function in the elderly. Pulse (Basel). 2013;1(1):29-34.

16. Papademetriou V: Hypertension and cognitive function. Blood pressure regulation and cognitive function: a review of the literature. Geriatrics 2005; 60: 20-22, 24.
17. Launer $\downarrow$, Masaki $K$, Petrovitch $H$, et al. The association between midlife blood pressure levels and late-life cognitive function. The HonoluluAsia Aging Study JAMA. 1995;274:1846-51.

18. Kilander L, Nyman $H$, Boberg $M$, et al. Hypertension is related to cognitive impairment: a 20-year follow-up of 999 men. Hypertension. 1998;31:780-6.

19. Cacciatore F, Abete $P$, Ferrara N, et al. The role of blood pressure in cognitive impairment in an elderly population. Osservatorio Geriatrico Campano Group J Hypertens. 1997;15:135-42.

20. Elias MF, Wolf PA, D'Agostino RB, et al. Untreated blood pressure level is inversely related to cognitive functioning: the Framingham study. Am J Epidemiol. 1993:138:353-64.

21. Heizhati M, Wang L, Li N, et al. Prevalence of mild cognitive impairment is higher in hypertensive population: a cross-sectional study in less developed Northwest China. Medicine (Baltimore). 2020;99(19):e19891.

22. Okusaga O, Stewart MC, Butcher I, et al. Smoking, hypercholesterolaemia and hypertension as risk factors for cognitive impairment in older adults. Age Ageing. 2013;42:306-11.

23. Uiterwijk R, Huijts M, Staals J, et al. Subjective cognitive failures in patients with hypertension are related to cognitive performance and cerebral micro bleeds. Hypertension. 2014;64:653-7.

24. Simona L, Francesco B, Fabrizio V, et al. Visit-to-visit variability in blood pressure and Alzheimer's disease. J Clin Hypertens. 2018:1-7.

25. Tully PJ, Yano Y, Launer LJ, et al. Association between blood pressure variability and cerebral small-vessel disease: a systematic review and meta-analysis. J Am Heart Assoc. 2020;9:e013841.

26. Lattanzi S, Luzzi S, Provinciali L, et al. Blood pressure variability in Alzheimer's disease and frontotemporal dementia: the effect on the rate of cognitive decline. J Alzheimers Dis. 2015:45:387-94.

27. Lattanzi S, ViticchiG FL, et al. Visit-to-visit blood pressure variability in Alzheimer disease. Alzheimer Dis Assoc Disord. 2014:28:347-51.

28. Böhm M, Schumacher H, Leong D, et al. Systolic blood pressure variation and mean heart rate is associated with cognitive dysfunction in patients with high cardiovascular risk. Hypertension. 2015;65(3):651-61.

29. Nagai M, Hoshide S, Ishikawa J, et al. Visit-to-visit blood pressure variations: new independent determinants for cognitive function in the elderly at high risk of cardiovascular disease. J Hypertens. 2012;30(8):1556-63.

30. Qin B, Viera AJ, Muntner P, et al. Visit-to-visit variability in blood pressure is related to late-life cognitive decline. Hypertension. 2016;68(1):106-13.

31. Sabayan B, Wijsman LW, Foster-Dingley JC, et al. Association of visitto-visit variability in blood pressure with cognitive function in old age: prospective cohort study. BMJ. 2013;347:f4600.

32. Yano $\mathrm{Y}$, Ning $\mathrm{H}$, Allen $\mathrm{N}$, et al. Long-term blood pressure variability throughout young adulthood and cognitive function in midlife: the coronary artery risk development in young adults (CARDIA) study. Hypertension. 2014;64(5):983-8.

33. Lattanzi S, Luzzi S, Provinciali L, et al. Blood pressure variability predicts cognitive decline in Alzheimer's disease patients. Neurobiol Aging. 2014;35(10):2282-7

34. Alpérovitch $\mathrm{A}$, Blachier $\mathrm{M}$, Soumaré $\mathrm{A}$, et al. Blood pressure variability and risk of dementia in an elderly cohort, the Three-City study. Alzheimers Dement. 2014:10:5330-7.

35. Kwon KY, Pyo SJ, Lee HM, et al. Cognition and visit-to-visit variability of blood pressure and heart rate in De novo patients with Parkinson's disease. J Mov Disord. 2016;9(3):144-51.

36. Kim Y, Lim JS, Oh MS, et al. Blood pressure variability is related to faster cognitive decline in ischemic stroke patients: PICASSO subanalysis. Sci Rep. 2021;11:5049.

37. Walker KA, Power MC, Gottesman RF. Defining the relationship between hypertension, cognitive decline, and dementia: a review. Curr Hypertens Rep. 2017;19:24.

38. ladecola C, Gottesman RF. Neurovascular and cognitive dysfunction in hypertension. Circ res. 2019 mar 29; 124(7):1025-1044. Wiesmann M, Kiliaan AJ, Claassen JA. Vascular aspects of cognitive impairment and dementia. J Cereb Blood Flow Metab. 2013:33:1696-706.

39. Rabkin SW. Arterial stiffness: detection and consequences in cognitive impairment and dementia of the elderly. J Alzheimers Dis. 2012;32:541-9.

40. Gorelick PB. Nyenhuis D; American Society of Hypertension. Writing G, Materson BJ, Calhoun DA, Elliott WJ, Phillips RA, Taler SJ, Townsend 
RR. Blood pressure and treatment of persons with hypertension as it relates to cognitive outcomes including executive function. Am Soc Hypertens. 2012;6:309-15.

41. Power MC, Weuve J, Gagne JJ, et al. The association between blood pressure and incident Alzheimer disease: a systematic review and meta-analysis. Epidemiology. 2011;22:646-59.

42. Pase MP, Herbert A, Grima NA, et al. Arterial stiffness as a cause of cognitive decline and dementia: a systematic review and meta-analysis. Intern Med J. 2012:42:808-15.

43. Guo Z, Fratiglioni L, Zhu L, et al. Occurrence and progression of dementia in a community population aged 75 years and older: relationship of antihypertensive medication use. Arch Neurol. 1999;56:991-6.

44. Tzourio C, Dufouil C, Ducimetière P, et al. Cognitive decline in individuals with high blood pressure: a longitudinal study in the elderly. EVA study group. Epidemiology of vascular aging. Neurology. 1999:53:1948-52.

45. Tadic M, Cuspidi C, Hering D. Hypertension and cognitive dysfunction in elderly: blood pressure management for this global burden. BMC Cardiovasc Disord. 2016;16:208.

46. Forte $G$, De Pascalis $V$, Favieri F, et al. Effects of blood pressure on cognitive performance: a systematic review. J Clin Med. 2020;9:34.

47. Seliger SL, Siscovick DS, Stehman-Breen CO, et al. Moderate renal impairment and risk of dementia among older adults: the cardiovascular health cognition study. J Am Soc Nephrol. 2004;15:1904-11.

48. Dos Santos CCC, Pedrosa R, Da Costa FA, et al. Análise da função cognitiva e capacidade functional em idosos hipertensos. Rev Bras Geriatr Gerontol. 2011;14(2):241-50.

49. Liao D, Cooper R, Cai J, et al. The prevalence and severity of white matter lesions, their relationship with age, ethnicity, gender, and cardiovascular disease risk factors: the ARIC study. Neuroepidemiology. 1997;16(3):149-62.

50. Harrington F, Saxby BK, McKeith IG, et al. Cognitive performance in hypertensive and normotensive older subjects. Hypertension. 2000;36(6):1079-82.

51. Haan MN, Weldon M. The influence of diabetes, hypertension, and stroke on ethnic differences in physical and cognitive functioning in an ethnically diverse older population. Ann Epidemiol. 1996;6(5):392-8

52. Elias MF, Robbins MA, Budge MM, et al. Studies of aging, hypertension and cognitive functioning, with contributions from the Maine-Syracuse Study. In: Costa PT, Siegler IC, eds. Advances in Cell Aging and Gerontology, Vol. 15, Recent Advances in Psychology and Aging. Amsterdam: Elsevier; 2004:89-131.

53. Waldstein SR, Katzel LI. Hypertension and cognitive function. In: Waldstein SR, Elias MF, editors. Neuropsychology of cardiovascular disease. Mahwah, NJ: Lawrence Erlbaum Associates; 2001. p. 15-36.

54. Swan GE, DeCarli C, Miller BL, et al. Association of midlife blood pressure and late-life cognitive decline and brain morphology. Neurology. 1998;51:986-93.

55. Waldstein SR. Hypertension and neuropsychological function: a lifespan perspective. Exp Aging Res. 1995;21:321-52.

56. Elias MF, Robbins MA, Schultz NR Jr, et al. Is blood pressure an important variable in research on aging and neuropsychological test performance? J Gerontol Psy Sci. 1990;45:128-35.

57. Elias MF, Wolf PA, D'Agostino RB, et al. Untreated blood pressure level is inversely related to cognitive functioning. Am J Epidemiol. 1993;138:353-63.

58. Swan GE, Carmelli D, Larue A. Systolic blood pressure tracking over 25 to 30 years and cognitive performance in older adults. Stroke. 1998:29:2334-40

59. Gorelick PB. Scuteri a, Black SE, et al; on behalf of the American Heart Association stroke council, council on epidemiology and prevention, council on cardiovascular nursing, council on cardiovascular radiology and intervention, and council on cardiovascular surgery and anesthesia. Vascular contributions to cognitive impairment and dementia: a statement for healthcare professionals from the American Heart Association/American Stroke Association. Stroke. 2011:42:2672-713.

60. Scheltens P, Blennow K, Breteler MM. Alzheimer's disease. Lancet. 2016;388:505-17.

61. Singer J, Trollor JN, Baune BT, et al. Arterial stiffness, the brain and cognition: a systematic review. Ageing Res Rev. 2014;15:16-27.
62. Hay M, Barnes C, Huentelman M, Brinton R, Ryan L. Hypertension and age-related cognitive impairment: common risk factors and a role for precision aging. Curr Hypertens Rep. 2020;22(10):80.

63. WHO. Global action plan on the public health response to dementia 2017-2025. [ISBN: 978-92-4-151348-7]. Geneva: World Health Organization, 2017

64. Faraco G, ladecola C. Hypertension: a harbinger of stroke and dementia. Hypertension. 2013;62:810-7.

65. Hugo J, Ganguli M. Dementia and cognitive impairment: epidemiology, diagnosis, and treatment. Clin Geriatr Med. 2014;30:421-42.

66. van Dijk EJ, Breteler MM, Schmidt R, et al. The association between blood pressure, hypertension, and cerebral white matter lesions: cardiovascular determinants of dementia study. Hypertension. 2004;44(5):625-30.

67. Pantoni L. Cerebral small vessel disease: from pathogenesis and clinical characteristics to therapeutic challenges. Lancet Neurol. 2010;9(7):689-701.

68. Schmidt EL, Burge W, Visscher KM, et al. Cortical thickness in frontoparietal and cingulo-opercular networks predicts executive function performance in older adults. Neuropsychology. 2016;30(3):322-31.

69. Arnsten AF, Wang MJ, Paspalas CD. Neuromodulation of thought: flexibilities and vulnerabilities in pre-frontal cortical network synapses. Neuron. 2012;76(1):223-39.

70. Moraes NC, Muela HCS, Memoria CM, et al. Systemic arterial hypertension and cognition in adults: effects on executive functioning. Arq Neuropsiquiatr. 2020;78(7):412-8.

71. Wong TY, Klein R, Sharrett AR, et al. Retinal microvascular abnormalities and cognitive impairment in middle-aged persons: the atherosclerosis risk in communities study. Stroke. 2002;33(6):1487-92.

72. Spence JD. Cerebral consequences of hypertension: where do they lead? J Hypertens Suppl. 1996 Dec;14(5):S139-45.

73. Skoog I. A review on blood pressure and ischaemic white matter lesions. Dement Geriatr Cogn Disord. 1998 Jul;9(Suppl 1):13-9.

74. Korf ES, White LR, Scheltens $P$, et al. Midlife blood pressure and the risk of hippocampal atrophy: the Honolulu Asia aging study. Hypertension. 2004:44:29-34.

75. Iadecola C, Yaffe K, Biller J. Et al; American Heart Association Counci on hypertension; council on clinical cardiology; council on cardiovascular disease in the young; council on cardiovascular and stroke nursing; council on quality of care and outcomes research; and stroke council. Impact of hypertension on cognitive function: a scientific statement from the American Heart Association. Hypertension. 2016;68(6):e67-94.

76. Goit RK, Ansari AH. Reduced parasympathetic tone in newly diagnosed essential hypertension. Indian Heart J. 2016;68:153-7.

77. O'Sullivan MRCP, Jones DK, Summers PE, et al. Evidence for cortical "disconnection" as a mechanism of age-related cognitive decline. Neurology. 2001;57:632-8.

78. Delano-Wood L, Bondi MW, Sacco J, et al. Heterogeneity in mild cognitive impairment: differences in neuropsychological profile and associated white matter lesion pathology. J Int Neuropsychol Soc. 2009:15:906-14.

79. Sierra C, De La Sierra A, Salamero M, et al. A Silent cerebral white matter lesions and cognitive function in middle-aged essential hypertensive patients. Am J Hypertens. 2004;17:529-34.

80. Bucur B, Madden DJ, Spaniol J, et al. Age-related slowing of memory retrieval: contributions of perceptual speed and cerebral white matter integrity. Neurobiol Aging. 2008;29:1070-9.

81. Brodaty H, Pond D, Kemp NM, et al. The GPCOG: a new screening test for dementia designed for general practice. J Am Geriatr Soc. 2002;50:530-4.

82. Golightly YM, Allen KD, Ambrose KR, et al. Physical activity as a vital sign: a systematic review. Physical Activity as a Vital Sign: A Systematic Review Prev Chronic Dis. 2017;14:170030.

83. Centers for Disease Control and Prevention. Division of Nutrition, Physical Activity, and Obesity. About Adult BMI. http://www.cdc.gov/healt hyweight/assessing/bmi/adult_bmi/

84. Chobanian AV, Bakris GL, Black HR. Seventh report of the joint national committee on prevention, detection, evaluation, and treatment of high blood pressure. Hypertension. 2003;42:1206-52. 
85. American Diabetes Association. Classification and diagnosis of diabetes. Sec. 2. In Standards of Medical Care in Diabetes-2015. Diabetes Care 2015; 38(Suppl. 1):S8-S16.

86. Fenton A, Montgomery E, Nightingale $\mathrm{P}$, et al. Glomerular filtration rate: new age- and gender-specific reference ranges and thresholds for living kidney donation. BMC Nephrol. 2018;19:336.

87. Khusun H, Yip R, Schultink W, Dillon DHS. World Health Organization hemoglobin cut-off points for the detection of Anemia are valid for an Indonesian population. J Nutr. 1999;129(9):1669-74.

88. Oh RC, Lanier JB. Management of hypertriglyceridemia. Am Fam Physician. 2007;75(9):1365-71.

89. Nantsupawat N, Booncharoen A, Wisetborisut A, et al. Appropriate Total cholesterol cut-offs for detection of abnormal LDL cholesterol and non-HDL cholesterol among low cardiovascular risk population. Lipids Health Dis. 2019;18(1):28.

90. Brucato A, Cianci F, Carnovale C. Management of hyperuricemia in asymptomatic patients: a critical appraisal. Eur J Intern Med. 2020;74:8-17.

91. Meschia JF, Bushnell CD, Boden-Albala B, et al. Guidelines for the primary prevention of stroke: a statement for healthcare professionals from the American Heart Association/American Stroke Association. Stroke. 2014;45:3754-832.

92. Sierra C, Coca A, Schiffrin EL. Vascular mechanisms in the pathogenesis of stroke. Curr Hypertens Rep. 2011;13:200-7.

93. McGuinness B, Todd S, Passmore P, et al. The effects of blood pressure lowering on development of cognitive impairment and dementia in patients without apparent prior cerebrovascular disease. Cochrane Database Syst Rev. 2006;19:CD004034.

94. Lindsay J, Laurin D, Verreault R, et al. Risk factors for Alzheimer's disease: a prospective analysis from the Canadian study of health and aging. Am J Epidemiol. 2002;156(5):445-53.

95. Morris MC, Scherr PA, Hebert LE, et al. Association of incident Alzheimer disease and blood pressure measured from 13 years before to 2 years after diagnosis in a large community study. Arch Neurol. 2001;58(10):1640-6.

96. Yasar S, Corrada M, Brookmeyer R, Kawas C. Calcium channel blockers and risk of AD: the Baltimore longitudinal study of aging. Neurobiol Aging. 2005;26(2):157-63.

97. Khachaturian AS, Zandi PP, Lyketsos CG, Hayden KM, Skoog I, Norton MC, et al. Antihypertensive medication use and incident Alzheimer disease: the Cache County study. Arch Neurol. 2006;63(5):686-92.

98. Peila R, White LR, Masaki K, Petrovitch H, Launer LJ. Reducing the risk of dementia: efficacy of long-term treatment of hypertension. Stroke. 2006;37(5):1165-70

99. Murray MD, Lane KA, Gao S, Evans RM, Unverzagt FW, Hall KS, et al. Preservation of cognitive function with antihypertensive medications: a longitudinal analysis of a community-based sample of African Americans. Arch Intern Med. 2002;162(18):2090-6.

100. Spinelli C, De Caro MF, Schirosi G, et al. Impaired cognitive executive dysfunction in adult treated hypertensives with a confirmed diagnosis of poorly controlled blood pressure. Int J Med Sci. 2014;11:771-8.

101. Chang-Quan H, Hui W, Chao-Min W, et al. The association of antihypertensive medication use with risk of cognitive decline and denmentia: a meta-analysis of longitudinal studies. Int J Clin Pract. 2011;65:1295-305.

102. Tzourio C, Anderson C, Chapman N, et al. PROGRESS collaborative group. Effects of blood pressure lowering with perindopril and in dapamide therapy on dementia and cognitive decline in patients with cerebrovascular disease. Arch Intern Med. 2003;163:1069-75.

103. Forette F, Seux ML, Staessen JA, et al. Systolic hypertension in Europe investigators. The prevention of dementia with antihypertensive treatment: new evidence from the systolic hypertension in Europe (Syst-Eur) study. Arch Intern Med. 2002;162:2046-52.

104. Gupta A, Perdomo S, Billinger S, et al. Treatment of hypertension reduces cognitive decline in older adults: a systematic review and meta-analysis. BMJ Open. 2020;10:e038971.

105. Gelber RP, Ross GW, Petrovitch H, et al. Antihypertensive medication use and risk of cognitive impairment: the Honolulu-Asia aging study. Neurology. 2013;81(10):888-95.

106. Duron E, Hanon O. Antihypertensive treatments, cognitive decline, and dementia. J Alzheimers Dis. 2010;20(3):903-14.
107. Peters R, Collerton J, Granic A, et al. Antihypertensive drug use and risk of cognitive decline in the very old: an observational study - the Newcastle 85+ study. J Hypertens. 2015;33(10):2156-64.

108. Birhanu TE, Kassa MA, Getachew B, et al. Prevalence and predictors of cognitive impairment among hypertensive patients on follow up at Jimma University medical center, Jimma, Southwest Ethiopia. EJCM. 2019:7(3):117-25.

109. Ballesteros RS. Actores individuales y colectivos asociados con la prevalencia de limitaciones funcionales del adulto mayor en Colombia: Análisis multinivel Análisismultinivel. Universidad del Rosario; 2017.

110. Sharifi F, Hedayat M, Fakhrzadeh $\mathrm{H}$, et al. Hypertension and cognitive impairment: Kahrizak elderly study. International Journal of Gerontology. 2011;5(4):212-6.

111. Wu L, He Y, Jiang B, et al. The association between the prevalence, treatment and control of hypertension and the risk of mild cognitive impairment in an elderly urban population in China. Hypertens Res. 2016;39:367-75.

112. Muela HC, Costa-Hong VA, Yassuda MS, et al. Hypertension severity is associated with impaired cognitive performance. J Am Heart Assoc. 2017:6(1):e004579.

113. Zahodne LB, Stern Y, Manly JJ. Differing effects of education on cognitive decline in diverse elders with low versus high educational attainment. Neuropsychology. 2015;29(4):649-57.

114. Saw YM, Saw TN, Than TM, et al. Cognitive impairment and its risk factors among Myanmar elderly using the revised Hasegawa's dementia scale: a cross sectional study in Nay Pyi Taw. Myanmar PLoS ONE. 2020;15(7):e0236656.

115. Maccora J, Peters R, Anstey KJ. What does (low) education mean in terms of dementia risk? A systematic review and meta-analysis highlighting inconsistency in measuring and operationalising education. SSM Popul Health. 2020;12:100654.

116. Livingston G, Sommerlad A, Orgeta V, et al. Dementia prevention, intervention, and care. Lancet. 2017:390(10113):2673-734.

117. Norton S, Matthews FE, Barnes DE, et al. Potential for primary prevention of Alzheimer's disease: an analysis of population-based data. Lancet Neurol. 2014;13(8):788-94.

118. Clouston SA, Glymour M, Terrera GM. Educational inequalities in agingrelated declines in fluid cognition and the onset of cognitive pathology. Alzheimers Dement (Amst). 2015 Sep 1;1(3):303-10.

119. Meng X, D'Arcy C. Education and dementia in the context of the cognitive reserve hypothesis: a systematic review with Meta-analyses and qualitative analyses. PLoS One. 2012;7(6):e38268.

120. Lövdén M, Fratiglioni L, Glymour MM, Lindenberger U, Tucker-Drob EM. Education and cognitive functioning across the life span. Psychol Sci Public Interest. 2020;21(1):6-41.

121. Matyas N, Keser Aschenberger F, Wagner $G$, et al Continuing education for the prevention of mild cognitive impairment and Alzheimer's-type dementia: a systematic review and overview of systematic reviews BMJ Open 2019:9:e027719.

122. Saenz JL, Downer B, Garcia MA, Wong R. Cognition and context: ruralurban differences in cognitive aging among older Mexican adults. J Aging Health. 2018;30(6):965-86.

123. Xiang $Y$, Zare $H$, Guan $C$, et al. The impact of rural-urban community settings on cognitive decline: results from a nationally-representative sample of seniors in China. BMC Geriatr. 2018;18:323.

124. Cassarino M, O'Sullivan V, Kenny RA, et al. Environment and cognitive aging: a cross-sectional study of place of residence and cognitive performance in the Irish longitudinal study on aging. Neuropsychology. 2016;30(5):543-57.

125. Peltzer K, Phaswana-Mafuya N, Pengpid S. Rural-urban health disparities among older adults in South Africa. Afr J Prim Health Care Fam Med. 2019;11(1):e1-6.

126. Contador I, Bermejo-Pareja F, Puertas-Martin V, Benito-Leon J. Childhood and adulthood rural residence increases the risk of dementia: NEDICES study. Curr Alzheimer Res. 2015;12(4):350-7.

127. Abner EL, Jicha GA, Christian WJ, Schreurs BG. Rural-urban differences in Alzheimer's disease and related disorders diagnostic prevalence in Kentucky and West Virginia. J Rural Health. 2016;32(3):314-20.

128. Kalaria RN, Maestre GE, Arizaga R, et al. Alzheimer's disease and vascular dementia in developing countries: prevalence, management, and risk factors. Lancet Neurol. 2008:7(9):812-26. 
129. Hall KS, Gao S, Unverzagt FW, Hendrie HC. Low education and childhood rural residence: risk for Alzheimer's disease in African Americans. Neurology. 2000;54(1):95-9.

130. Liu CC, Liu CH, Sun Y, et al. Rural-urban disparities in the prevalence of mild cognitive impairment and dementia in Taiwan: a door-to-door nationwide study. J Epidemiol. 2021 Apr;10.

131. Chuang YF, Liu YC, Tseng HY, et al. Urban-rural differences in the prevalence and correlates of mild cognitive impairment in communitydwelling older adults in Taiwan: the EMCIT study. J Formos Med Assoc. 2021;S0929-6646(21):00110-8.

132. Nakamura K, Kitamura K, Watanabe $Y$, et al. Rural-urban differences in the prevalence of cognitive impairment in independent communitydwelling elderly residents of Ojiya city, Niigata prefecture, Japan. Environ Health Prev Med. 2016;21(6):422-9.

133. Vance DE, Bail J, Enah CC, et al. The impact of employment on cognition and cognitive reserve: implications across diseases and aging. Nursing: Research and Reviews. 2016;6:61-71.

134. Bonsang E, Adam S, Perelman S. Does retirement affect cognitive functioning? J Health Econ. 2012;31:490-501.

135. Finkel D, Andel R, Gatz M, Pedersen NL. The role of occupational complexity in trajectories of cognitive aging before and after retirement. Psychol Aging. 2009;24(3):563-73.

136. Roberts BA, Fuhrer R, Marmot M, Richards M. Does retirement influence cognitive performance? The Whitehall II study. J Epidemiol Community Health. 2010.

137. Wickrama KAS, O'Neal CW, Kwag KH, Lee TK. Is working later in life good or bad for health? An investigation of multiple health outcomes. J Gerontol B Psychol Sci Soc Sci. 2013

138. Xue B, Cadar D, Fleischmann M, Stansfeld S, Carr E, Kivimäki M, et al. Effect of retirement on cognitive function: the Whitehall II cohort study. Eur J Epidemiol. 2018:33(10):989-1001.

139. Sarabia-Cobo CM, Pérez V, Hermosilla C, de Lorena P. Retirement or no retirement? The Decision's effects on cognitive functioning, well-being, and quality of life. Behav Sci (Basel). 2020;10(10):151.

140. Leist AK, Glymour MM, Mackenbach JP, van Lenthe FJ, Avendano M. Time away from work predicts later cognitive function: differences by activity during leave. Ann Epidemiol. 2013;23(8):455-62.

141. Etgen T, Chonchol M, Forstl H, et al. Chronic kidney disease and cognitive impairment: a systematic review and meta-analysis. Am J Nephrol. 2012;35:474-82.

142. Brodski J, Rossell SL, Castle DJ, Tan EJ. A systematic review of cognitive impairments associated with kidney failure in adults before natural agerelated changes. J Int Neuropsychol Soc. 2019;25(1):101-14.

143. Van Sandwijk MS, Ten Berge IJ, Majoie CB, et al. Cognitive changes in chronic kidney disease and after transplantation. Transplantation. 2016;100(4):734-42

144. Bossola M, Antocicco M, Di Stasio E, et al. Mini mental state examination over time in chronic hemodialysis patients. J Psychosom Res. 2011:71(1):50-4.
145. Buchman AS, Tanne D, Boyle PA, et al. Kidney function is associated with the rate of cognitive decline in the elderly. Neurology. 2009:73(12):920-7.

146. Kurella M, Chertow GM, Fried LF, et al. Chronic kidney disease and cognitive impairment in the elderly: the health, aging, and body composition study. J Am Soc Nephrol. 2005;16(7):2127-33.

147. Gela YY, Getu AA, Adane A, et al. Cognitive impairment and associated factors among chronic kidney disease patients: a comparative crosssectional study. Neuropsychiatr Dis Treat. 2021;17(12):1483-92.

148. Aggarwal HK, Jain D, Bhavikatti A. Cognitive dysfunction in patients with chronic kidney disease. Saudi J Kidney Dis Transpl. 2020;31:796-804

149. Pépin M, Villain C. Maladie rénale chronique et troubles neurocognitifs [Chronic kidney disease and cognitive impairment]. Geriatr Psychol Neuropsychiatr Vieil. 2020;18(4):429-35.

150. da Matta SM, Janaina Matos M, Kummer AM, Barbosa IG, Teixeira AL, Silva AC. Cognitive alterations in chronic kidney disease: an update. J Bras Nefrol. 2014;36(2):241-5.

151. Yaffe K, Ackerson L, Kurella Tamura M, et al. Chronic kidney disease and cognitive function in older adults: findings from the chronic renal insufficiency cohort cognitive study. J Am Geriatr Soc. 2010;58:338-45.

152. Kurella Tamura $M$, Xie $D$, Yaffe $K$, et al. Vascular risk factors and cognitive impairment in chronic kidney disease: the chronic renal insufficiency cohort (CRIC) study. Clin J Am Soc Nephrol. 2011;6:248-56.

153. Da Silva ST, Ribeiro Rde C, Rosa Cde O, et al. Cognitive capacity in individuals with chronic kidney disease: relation to demographic and clinical characteristics. J Bras Nefrol. 2014:36:163-70.

154. Kerr E, Craig D, Mcguinness B, et al. Reduced estimated glomerular filtration rate in alzheimer's disease. Int J Geriatr Psychiatry. 2009;24:927-32.

155. Kunschmann R, Busse S, Frodl T, et al. Psychotic symptoms associated with poor renal function in mild cognitive impairment and dementias. J Alzheimers Dis. 2017:58:243-52.

156. Simões E, Silva AC, Miranda AS, Rocha NP, et al. Neuropsychiatric disorders in chronic kidney disease. Front Pharmacol. 2019;10:932

157. Bugnicourt JM, Godefroy O, Chillon JM, et al. Cognitive disorders and dementia in CKD: the neglected kidney-brain axis. J Am Soc Nephrol. 2013:24(3):353-63.

158. O'lone E, Connors M, Masson P, et al. Cognition in people with endstage kidney disease treated with hemodialysis: a systematic review and meta-analysis. Am J Kidney Dis. 2016;67:925-35.

\section{Publisher's Note}

Springer Nature remains neutral with regard to jurisdictional claims in published maps and institutional affiliations.
Ready to submit your research? Choose BMC and benefit from:

- fast, convenient online submission

- thorough peer review by experienced researchers in your field

- rapid publication on acceptance

- support for research data, including large and complex data types

- gold Open Access which fosters wider collaboration and increased citations

- maximum visibility for your research: over $100 \mathrm{M}$ website views per year

At BMC, research is always in progress.

Learn more biomedcentral.com/submissions 